\title{
Perception of Nuclear Energy and Coal in France and the Netherlands
}

\author{
Oene Wiegman, ${ }^{1}$ Jan M. Gutteling, ${ }^{1}$ and Bernard Cadet ${ }^{2}$
}

Received October 7, 1994; revised May 5, 1995

\begin{abstract}
This study focuses on the perception of large scale application of nuclear energy and coal in the Netherlands and France. The application of these energy-sources and the risks and benefits are judged differently by various group in society. In Europe, France has the highest density of nuclear power plants and the Netherlands has one of the lowest. In both countries scientists and social scientists completed a questionnaire assessing the perception of the large scale application of both energy sources. Furthermore, a number of variables relating to the socio cultural and political circumstances were measured. The results indicate that the French had a higher risk perception and a more negative attitude toward nuclear power than the Dutch. But they also assess the benefits of the use of nuclear power to be higher. Explanations for these differences are discussed.
\end{abstract}

KEY WORDS: Risk perception; nuclear power; coal; cross-national.

\section{INTRODUCTION}

In this study we will compare the reactions of French and Dutch respondents toward the large scale application of nuclear energy and coal. It is evident that in the last two or three decades nuclear energy has been faced with public scepticism. In many studies risk attitudes toward use of nuclear energy were demonstrated to be multidimensional and to include some distinction between hazards and benefits. Otway and Fishbein ${ }^{(1)}$ reported four factors, not fully independent, which reflected both risks and benefits: psychological risk, sociopolitical consequences, environmental effects and technical and economic benefits. Thomas et al.' $\mathrm{s}^{(2)}$ subjects judged five sources of energy on a large number of attributes. On the basis of a factor analysis, the authors differentiated three risk dimensions, psychological and physical hazards, indirect hazards (e.g., in the political sense), and environmental hazards and two benefit dimensions, economic benefits and technological bene-

\footnotetext{
1 University of Twente, Department of Psychology, P.O. Box 217, 7500 AE Enschede, the Netherlands.

${ }^{2}$ Department of Psychology, University of Caen, France.
}

fits. An interesting result from this study was that benefits and risks were not directly related. In the Netherlands, Meertens and Stallen ${ }^{(3)}$ found two factors which they termed 'evaluation of social and societal consequences' and 'evaluations of technical and economic consequences'. In another study, Midden ${ }^{(4)}$ concluded that the public is primarily concerned with threats to safety and that the benefits are always considered less important. It should be noted that Slovic ${ }^{(3)}$, following a methodologically different approach to assess expressed preferences toward a large number of hazardous technologies and activities, also found that 'dread risk' was the most important factor with respect to the perception of the risks of nuclear power. A study by Daamen and $\mathrm{Kips}^{(6)}$ indicates that in recent years representative samples of the Dutch public have had predominantly negative attitudes toward nuclear power. And after the Chernobyl accident in 1986, the support of nuclear energy dropped even more and only recovered slightly thereafter.() This accident has deeply affected perceptions and attitudes towards nuclear power and convinced people that this technology is unsafe and undesirable. From 1986 to 1993 , approximately $60 \%$ of the Dutch population had a negative attitude toward the large scale 
application of nuclear energy. Almost $90 \%$ is opposed to building new nuclear power plants in the Netherlands.

The situation in France in this respect might be different. In 1991, Weinberg(8) published a remarkable article in which he observed an atmosphere of acceptance in France toward nuclear power compared to other countries in Europe. He states that in England the public is increasingly sceptical, in Germany and the Netherlands nuclear's future hangs in the balance and in Scandinavia it has been officially rejected. Weinberg ${ }^{(8)}$ offers three explanations for the positive attitude he observes in France. In part, it should be attributed to the extraordinary success of its nuclear enterprises and the highly rational organization of the French nuclear program. The French public would seem to take great pride in this success especially since the view is widely hold in France that nuclear energy is a French invention. Indeed, the successes of the French nuclear enterprise cannot be denied; In Europe, France has the highest density of nuclear power plants. More than $70 \%$ of its electricity is generated by nuclear power and more than 56 reactors are operational. Five more reactors are under construction. Whereas in the Netherlands, only two reactors are operational and none are under construction. About 2 percent of Dutch electricity is generated by nuclear power. Weinberg(8) further suggests that the power of the central government may play an important role in public acceptance. France has an elite upper bureaucracy who not only is in a position to run the nuclear establishment but is accepted and trusted by the man in the street. Nuclear power seems to do best where the underlying political structure is elitist and authoritarian. In this political climate environmentalists, although being able to organize a number of major anti nuclear demonstrations in the 1970s, are not a factor of political importance. ${ }^{(9)}$ Weinberg ${ }^{(8)}$ concludes that in a country where the tradition is open and anti authoritarian like in the Netherlands the opposition to nuclear energy is powerful enough to stop the nuclear enterprise. When the tradition is closed and authoritarian which he assumes is the case in France, opposition to nuclear energy seems to be largely muted or absent. On the basis of this assumption large differences in resistance toward nuclear energy between France and the Netherlands can be expected. A third reason is the lack in France of alternative sources of energy and its dependency upon imported oil. However, the Netherlands too are very dependent on imported oil and coal. So, no differences between France and the Netherlands are expected in this regard.

It should be emphasized, however, that Weinberg's conclusions are not based on empirical studies in which the (risk) perception of the public in the various coun- tries is assessed. It is remarkable that there exists a clear discrepancy between Weinberg's observation of the French situation and the results of empirical studies in that country. ${ }^{(9,10)}$ Karpowicz-Lazreg and Mullet ${ }^{(10)}$ report a study in which the reactions of French students toward the risks of nuclear energy are compared to the risk perception of American subjects. Previous studies have shown that Americans in general have a negative attitude toward nuclear power. ${ }^{(5)}$ Slovic ${ }^{(5)}$ demonstrated that in the US nuclear power scores high on 'perceived dread' and concluded that the more technically countries are developed, the more negative the reactions of the public toward technology will be. Karpowicz-Lazreg and Mullet found that Americans and French did not differ in their assessment of the risks of nuclear energy. In both countries these risks are seen as rather great, compared to technically less developed countries as Norway and Poland. Bastide et al. ${ }^{(9)}$ report that $63 \%$ of a French representative sample of 18 years and older indicated that the risks of nuclear plants are dangerous. From the two empirical studies, it could be concluded that the French take a rather negative position toward nuclear energy, which is contradictory to the observations of Weinberg. ${ }^{(8)}$

Weinberg offers two socio cultural explanations which might explain the positive attitude of the French public toward nuclear energy, namely the centralistic authoritarian political system and the French taking pride in nuclear energy because they perceive it as a French invention. However, two other explanations for the positive French perception assumed by Weinberg, can be mentioned. Firstly, the relative large density of nuclear power plants in France implies a great probability that the average French citizen lives relatively close to a nuclear power plant. Research in several countries has shown that under normal operating conditions, people living close to an existing nuclear power plant assess this form of energy production to be more acceptable than people living far away..$^{(11,12,13,14)}$ Rogers ${ }^{(15)}$ offers a number of assumptions to explain the unexpected positive attitude of people living in the vicinity of nuclear power plants; (a) the residents of a nuclear plant area, on the basis of their own personal experience of living with the potential hazard and the inherent low probability of an accident, assign a lower probability to the risks associated with nuclear power plants; (b) on the basis of the cognitive dissonance theory, ${ }^{(16)}$ which posits that enhanced risk acceptability is a function of reconciling a forced choice acceptance, it can be assumed that the cognitive dissonance that occurs by not migrating from the risk area, and therefore by accepting the risks of nuclear power, is reduced by estimating the risks less highly; (c) 
people living near to the risk area have a preference for/or are economically dependent on nuclear energy, and therefore have a more positive attitude towards it; (d) people living in the neighbourhood of the hazard are more altruistic and willing to consider the interests of society, implying a more positive attitude toward nuclear energy. By using a series of log-linear models Rogers found no empirical support for the cognitive dissonance explanation and for the altruistic explanation. Rogers ${ }^{(15)}$ did find weak evidence for the other two, i.e. nuclear neighbours are positively reinforced toward lower perceived risk through living with the non-realized risks, or enjoy and perhaps know someone else who enjoys the economic benefits of nuclear power. Especially in France, with its successful nuclear programme and the high density of nuclear power plants, relatively much people benefit directly or indirectly from the use of this energy source.

Another possible explanation is based on the impact of the mass media, according to Bandura's social learning theory. ${ }^{(17)}$ Bandura states that the high advances in the technology of communication have greatly increased the role played by vicarious learning from the symbolic environment. Bandura also stressed the importance of the mass media in impeding as well as promoting innovation processes and shaping people's perception of technological risks. Bandura states that the vicarious induction of fears has more profound societal consequences than direct experience, because the vicarious mode can affect the lives of a vast number of people. Singer and Endreny ${ }^{(18)}$ established that in news reports about environmental hazards, potential harms were almost always mentioned (property damage, illness, injury and death), but seldom information was given about benefits. In this way the media are superb at evoking the serious outcomes associated with a specific instance of a hazard and they have a preoccupation with bad news. On the basis of social learning theory it can be assumed that this negative bias in media reporting of technological risks will negatively bias the reactions of the receivers who are exposed regularly and frequently to this information. Wiegman et al. ${ }^{(19)}$ established that readers of a newspaper with the highest hazard coverage, compared to those who read a newspaper with the lowest hazard coverage, had a more negative attitude towards these risks, perceived them as more threatening, showed more feelings of insecurity, were more inclined to seek information and less inclined to avoid the hazards. This study strongly supports the hypothesis for a negative mass media influence on perceptions of technological hazards. On the basis of the assumption of mass media impact, the observed difference in reactions between
France and the Netherlands could be attributed to differences in mass media coverage of nuclear energy. However, no research is known in which mass media coverage of nuclear energy in France and the Netherlands is studied. The particular relevance of communication processes through the mass media is underlined also in the social amplification of risk model, proposed by Kasperson et al. ${ }^{(20)}$. The focal point of this model is that hazard driven events interact with psychological, social, institutional, and cultural processes in ways that can heighten or attenuate individual and social perceptions of risk and shape risk behavior. Behavioral patterns, in turn, generate secondary social or economic consequences that extend far beyond direct harm to humans or the environment, including significant indirect impacts such as liability, insurance costs, loss of trust in institutions, or alienation from community affairs. The process starts with either a physical event or the recognition of an adverse effect, which is communicated. Individuals, groups and institutions (e.g. mass media) collect and respond to this information about risks, and act as amplification stations through behavioral responses or communication. Renn et al. ${ }^{(21)}$ performed an empirical study into the relationship between five sets of variables relevant in the social amplification framework, namely physical consequences, risk perceptions, media coverage, public responses, and societal impacts. One of the results of this study was a strong positive correlation between amount of mass media coverage and perception of dread posed by hazards, which is in accordance with the previously mentioned study by Wiegman et al.(19)

Taking into account the contradiction between the previously mentioned empirical studies in France and Weinberg' ${ }^{(8)}$ conclusions of the perception of nuclear energy in France, and the scepticism of the Dutch toward nuclear energy, ${ }^{(6)}$ we decided to study the perception of nuclear energy in these two countries. In line with Weinberg we will explore socio cultural processes, as well as mass media coverage, and the effect of the density of nuclear power plants as explanations for differences in countries. The density of nuclear power plants differs quire remarkably in France and the Netherlands. Approximately, in France there is one nuclear power plant for every million citizens, in the Netherlands there is one for every 7.5 million inhabitants. We will also assess the risk perception and attitudes toward a less controversial source of energy, namely coal, as was done in previous studies also ${ }^{(4,6.14)}$ providing a comparison of risk assessments between the energy sources. It should be stressed, however, that an energy source like coal also has negative consequences, because coal fired energy plants contribute to acidification and emit greenhouse gasses. 
These risks are also reflected in the attitudes of the public toward the large scale application of coal. ${ }^{(6)}$ In the Netherlands, since 1990 between $60 \%$ or $70 \%$ of the people are also opposed toward the large scale application of coal. However, in spite of the fact that the majority of the population seems to reject coal as a source of large scale energy production too, it has never led to the enormous amount of public opposition as was the case with nuclear energy, which makes it an interesting issue for comparison risk attitudes and perceptions. In the Netherlands, $97 \%$ of the electricity is generated by fossil fuelled plants among which natural gas (49\%), oil $(35 \%)$ and coal $(11 \%)$ are the most important energy sources. $^{(22)}$ In France, fossil fuels play a minor role in the electricity generation (natural gas $2,4 \%$, oil $1,4 \%$ and coal about $7 \%$ ).

\section{METHOD}

\subsection{Subjects}

This study aims at establishing risk perceptions and attitudes toward nuclear energy and coal. The subjects in this study should be able to formulate a well funded assessment of these two sources of energy. The probability of finding an extremely skewed distribution of opponents and supporters of nuclear energy in the general public in the Netherlands would be rather large. Therefore, we decided not to take a sample from the general public, but to ask scientists and social scientists to participate in our study. These target groups were also used in another Dutch study, ${ }^{(3)}$ in which was found that the distribution of opponents and supporters of nuclear power in both groups was comparable. So, it is assumed that in our study this will also be the case. In both France and the Netherlands, 250 names of scientists and social scientists were randomly selected from universities in the capital and the northern, southern, western and eastern part of the country. These persons were mailed a questionnaire. Respondents who worked at nuclear or coal engineering departments were excluded. It should be noted here that this procedure strictly speaking means that our data don't reflect the attitudes toward nuclear power or coal of the general populations of France or the Netherlands.

\subsection{Variables Pertaining to the Perception of Nuclear Energy and Coal}

Probability of Risks and Benefits. Five questions on 7-point scales (with extremes very small-very large) fo- cused on the subjects assessment of the probability of risks (in case of an accident the contamination of an area with a diameter of $5 \mathrm{~km}$; in case of an accident a larger number of children with birth defects; in case of an accident a large scale evacuation; contamination of agricultural resources and ground water; negative consequences for the environment). The questions were based on the study of Verplanken. ${ }^{(7)}$ These five questions formed a very reliable scale $(\alpha=0.90)$ for nuclear energy and a reliable scale for coal $(\alpha=0.75)$.

Five other questions focused on the subjects assessment of the probability of benefits (large economic benefits; an increase in jobs; lower electricity prices; progress of science; preservation of other fossil fuels). These five questions formed satisfactory scales $(\alpha=$ $0.67, \alpha=0.66$ ) for nuclear energy and coal, respectively.

Attitude. Four questions aimed to assess the respondents' attitude toward the large scale application of both the energy sources. Subjects indicated on 5-point scales (with extremes agree very much-disagree very much) whether the large scale application of both the energy sources in their own country would arouse fear, whether the application of nuclear energy or coal in their own neighbourhood would arouse fear, whether the consequences of an accident in a nuclear or coal fired plant would be controllable or whether nuclear or coal fired power plants would be unsafe for residents. The four questions formed satisfactory scales $(\alpha=0.74, \alpha=$ 0.70 ) for nuclear energy and coal, respectively.

Behavioral Intentions. In total six types of behavioral intentions with respect to risk mitigating behaviour toward nuclear energy and coal were formulated, based on previous environmental hazards research. ${ }^{(23,24)}$ Subjects indicated on 5-point scales (with extremes definitely yes-definitely not) whether in case of a governmental plan to increase the number of nuclear or coal fired power plants in their country, they would intent to take each of the following mitigating behaviours; protesting with the local council, taking legal action, addressing a power plant, discussing the risks with colleagues, addressing the environmental inspectorate or a group of environmental activists. The six questions formed reliable scales $(\alpha=0.82, \alpha=0.81)$ for nuclear energy and coal, respectively.

Self-Efficacy. Toward each of the types of mitigating behavior, subjects indicated on 5-point scales (with extremes definitely yes - definitely not) their assessment of their own capabilities to adopt the specific behaviour (self efficacy). The importance of the concept of self efficacy for the subjective assessment of risks was demonstrated elsewhere. ${ }^{(25)}$ Both measures were based on 
Table I. Sample Characteristics

\begin{tabular}{lccc}
\hline Characteristics & Netherlands & France & $\begin{array}{c}\text { Level of } \\
\text { significance }\end{array}$ \\
\hline Percentage social scientists & $48.5 \%$ & $58.6 \%$ & $\mathrm{~ns}$ \\
Male respondents $^{\text {Average personal experience nuclear energy }}{ }^{a}$ & $79.2 \%$ & $48.8 \%$ & $p<.001$ \\
Average professional experience nuclear energy $^{a}$ & 1.3 & 1.3 & $\mathrm{~ns}$ \\
Average personal experience coal $^{a}$ & 1.5 & 1.6 & $\mathrm{~ns}$ \\
Average professional experience coal $^{a}$ & 1.2 & 1.2 & $\mathrm{~ns}$ \\
\hline
\end{tabular}

${ }^{a}$ On a 5-point scale with extremes:very little (1)-very large (5).

previous research with respect to reactions to the confrontation with an environmental hazard. ${ }^{(23)}$ The six questions formed very reliable scales $(\alpha=0.87, \alpha=$ 0.89 ) for nuclear energy and coal, respectively.

\subsection{Variables Relating to Sociocultural and Political Circumstances}

Mass Media Coverage and Exposure. Subjects indicated on 9-point scales (with extremes very seldomvery often) whether four news media in their country (newspapers, television, radio and scientific/professional journals) covered the large scale application of energy sources in general. Furthermore, the respondents indicated whether they exposed themselves to information about the large scale application of nuclear energy and coal in these media. The questions relating to the coverage of energy sources in general in the four media formed a reliable scale $(\alpha=0.80)$. The questions relating to "exposure to nuclear energy coverage in the four media' formed a satisfactory scale $(\alpha=0.69)$. The questions relating to 'exposure to coal coverage in the four media' formed a reliable scale $(\alpha=0.82)$.

Governmental Policy. Questions were directed at the subjects assessment of the position of their countries government and the EC toward the energy sources. On 5-point scales (with extremes agree very much-disagree very much) subjects indicated whether their country's government had a positive attitude toward the large scale application of the energy source, the EC had a positive attitude, their country's government was able to control the large scale application of the energy source, their country's government provides credible information about the large scale application, or whether their country's government wants to regulate the large scale application too much, and whether their country, compared to other European countries, was ahead technologically with respect to nuclear energy or coal. Analysis of these questions indicated that no sufficiently reliable scales could be formed of these items (nuclear energy $\alpha$ $=0.59$; coal $\alpha=0.45$ ), and consequently the items will be analyzed separately.

Attitudes Towards Science and Technology. In total, six questions were aimed at the subjects attitude to science and technology. On 5-point scales (with extremes agree very much - disagree very much) subjects indicated whether in their opinion science and technology contribute to society's welfare, to economic development, to the progress of society, or the solution of societal problems. Furthermore, the respondents indicated whether in the future science and technology would solve its own risks. Finally, the respondents indicated whether society's welfare would have reached its present level without science and technology. The six questions formed a reliable scale $(\alpha=0.82)$.

\section{RESULTS}

\subsection{Sample Characteristics}

In total, 187 subjects completed a questionnaire, of which 101 were Dutch. Table I contains the most important characteristics of these subjects. Table I indicates that on most characteristics French and Dutch subjects are comparable. The only exception is gender, $51 \%$ of the French subjects are female, where as only $21 \%$ of the Dutch subjects are. The comparative analysis between countries will be of the analysis of covariance type, with gender as covariate. Most of the respondents did not have personal or professional experiences with the large scale application of the sources of energy. This was neither the case for the scientists. In general, no significant differences were found between the scientists and social scientists for most variables. The only exception was that the scientists assessed the probability of the benefits in applying nuclear power to be higher than the social scientists $(F(1,184)=8.53, p<.01)$. 
Table II. Reactions Toward the Large-Scale Application of Nuclear Energy and Coal

\begin{tabular}{|c|c|c|c|c|c|c|}
\hline & \multicolumn{3}{|c|}{ Nuclear energy } & \multicolumn{3}{|c|}{ Coal } \\
\hline & Netherlands & France & $\begin{array}{l}\text { Sign. of } \\
\text { difference }\end{array}$ & Netherlands & France & $\begin{array}{l}\text { Sign. of } \\
\text { difference }\end{array}$ \\
\hline Multivariate & & & $* * *$ & & & $* * *$ \\
\hline \multicolumn{7}{|l|}{ Univariate } \\
\hline Attitude ${ }^{a}$ & 3.6 & 4.0 & $* * *$ & 3.0 & 2.3 & $* * *$ \\
\hline Risks $^{a}$ & 3.6 & 4.2 & $* * *$ & 2.7 & 2.2 & $* * *$ \\
\hline Benefits $^{a}$ & 4.6 & 4.0 & $* * *$ & 5.1 & 5.4 & $p<.10$ \\
\hline Behavioral intentions $^{a}$ & 2.5 & 3.2 & $* * *$ & 2.3 & 2.7 & $* * *$ \\
\hline Self efficacy ${ }^{b}$ & 2.8 & 2.1 & $* * *$ & 2.7 & 1.9 & $* * *$ \\
\hline
\end{tabular}

Dividing the respondents into opponents and supporters for that specific source of energy, no significant differences were found for gender (nuclear energy $\mathrm{F}(2,147)=0.28$, ns; coal $\mathrm{F}(2,143)=0.50, \mathrm{~ns})$, country (nuclear energy $\mathrm{F}(2,147)=1.75$, ns; coal $\mathrm{F}(2,143)=$ 1.13 , ns) and professional group (nuclear energy $F(2,147)=0.38$, ns; coal $F(2,143)=1.52, n s)$. As expected opponents do have a more negative attitude toward that specific source of energy than supporters (nuclear energy: $F(2,147)=21.12, p<.001$; coal: $F(2,143)=9.33, p<.001)$ and assess the expertise of the government of their country in this area to be lower (nuclear energy: $F(2,147)=8.12, p<.001$; coal: $\mathrm{F}(2,143)=3.55, \mathrm{p}<.05)$. Moreover, opponents of nuclear power rate the information of their government about nuclear power to be less credible $(F(2,147)=$ $11.64, p<.001)$ and have a stronger intention to seek information and to protest $(F(2,147)=6.63, p<.01)$.

\subsection{Differences Between France and the Netherlands}

In Table II, the differences between the subjects from both countries with regard to the application of nuclear power and coal are depicted, using sexe as a covariate. Multivariately, a significant difference between both countries was found $(F(5,170)=19.8, p<$ $.001)$. French respondents assess the probability of risks of nuclear power to be higher than the Dutch $(F(1,174)$ $=4.60, p<.05)$, but they also rate the probability of the benefits to be higher $(F(1,174)=19.57, p<.001)$. The French also show a more negative attitude toward nuclear power $(F(1,174)=3.17, p<.10)$ and a stronger intention to mitigate the risk $(\mathrm{F}(1,174)=27.29, \mathrm{p}<$ $.001)$. However, the French feel less capable than the Dutch to perform this type of behaviour $(F(1,174)=$ 26.85, $\mathrm{p}<.001$ ).

Inspecting the results with regard to coal we establish that its risks are assessed significantly lower than for nuclear power and that the attitude toward coal is also less negative. The French do have a more positive attitude toward the use of coal than the Dutch $(F(1,172)$ $=17.84, \mathrm{p}<.001$ ), and they assess the probability of risks to be lower $(F(1,172)=12.41, p<.001)$. Moreover, the French also tend to assess the benefits of coal to be lower $(\mathrm{F}(1,172)=3.13, \mathrm{p}<.10)$. The French show a less strong intention to risk mitigating behaviour toward coal than the Dutch $(\mathrm{F}(1,172)=12.91, \mathrm{p}<$ $.001)$ but they feel less capable to perform this behaviour $(\mathrm{F}(1,172)=22.48, \mathrm{p}<.001)$.

In Table III, the results with respect to the assessment of governmental policy are shown. Significant differences between the French and Dutch respondents are found toward nuclear power as well as toward coal. The French subjects' rating of their government toward nuclear energy is more positive than for the Dutch subjects $(F(1,170)=75.66, p<.001)$. For the rating of the policy of the EC also a significant difference between the two countries was found in the same direction $(F(1,170)$ $=8.13, \mathrm{p}<.01)$. Moreover, no difference exists between the two countries with regard to the assessment of the government's expertise $(\mathrm{F}(1,170)=0.69$, ns $)$ and the credibility of the information which is distributed by the government about the application of nuclear energy $(\mathrm{F}(1,170)=0.84, \mathrm{~ns})$. More than the Dutch, the French rate that their own government wants to regulate the application of nuclear power $(\mathrm{F}(1,170)=15.85, \mathrm{p}<.001)$. 
Table III. Reactions Toward Governmental Policy Regarding Nuclear Energy and Coal

\begin{tabular}{|c|c|c|c|c|c|c|}
\hline & \multicolumn{3}{|c|}{ Nuclear energy } & \multicolumn{3}{|c|}{ Coal } \\
\hline & Netherlands & France & $\begin{array}{l}\text { Sign. of } \\
\text { difference }\end{array}$ & Netherlands & France & $\begin{array}{l}\text { Sign. of } \\
\text { difference }\end{array}$ \\
\hline \multicolumn{7}{|l|}{ Univariate } \\
\hline Own government positive & 2.7 & 3.9 & $* * *$ & 2.8 & 2.5 & ** \\
\hline EC positive & 3.2 & 3.6 & $* *$ & 2.8 & 2.6 & ns \\
\hline Own government's expertise & 3.0 & 3.0 & ns & 2.5 & 2.7 & ns \\
\hline $\begin{array}{l}\text { Credibility of information own } \\
\text { government }\end{array}$ & 3.1 & 3.2 & ns & 2.8 & 3.1 & $*$ \\
\hline $\begin{array}{l}\text { Own government wants to } \\
\text { regulate }\end{array}$ & 2.2 & 2.9 & $* * *$ & 2.3 & 2.7 & $* *$ \\
\hline Own country's leading position & 1.4 & 2.5 & $* * *$ & 1.8 & 1.6 & ns \\
\hline
\end{tabular}

a A higher score indicates more agreement with the item's statement.

${ }^{*} p<.05$.

$* * p<.01$.

$* * * p<.001$.

Table IV. Reactions Toward Science and Technology

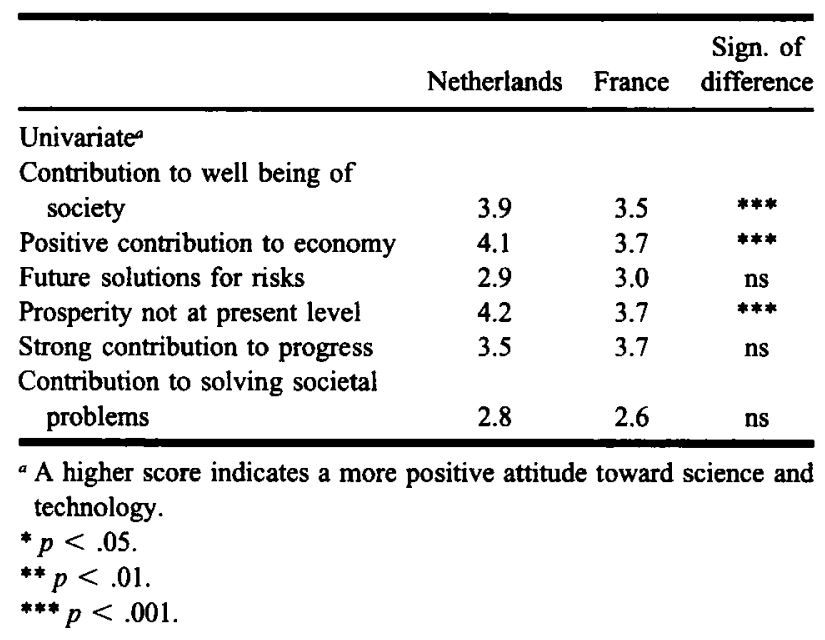

More than the Dutch, the French assess their own country to have a leading position in Europe with respect to the application of nuclear power $(F(1,170)=55.87, p$ $<.001)$.

With respect to the application of coal the Dutch rate their own government to take a more favourable position, compared to the French rating of their government. The French rate the credibility of the information of their own government about coal to be higher than the Dutch $(F(1,170)=3.16, p<.10)$. And more than the Dutch, the French indicate that their own government wants to regulate the application of coal $(F(1,170)$ $=5.39, \mathrm{p}<.05)$.

Table IV contains the results of the questions relating to science and technology. In general, the French
Table V. Perceived Media Coverage Regarding Energy Sources in General

\begin{tabular}{lccc}
\hline & Netherlands & France & $\begin{array}{c}\text { Sign. of } \\
\text { difference }\end{array}$ \\
\hline Univariate & & & \\
Newspapers & 5.4 & 4.4 & $* * *$ \\
Television & 4.7 & 4.5 & $\mathrm{~ns}$ \\
Radio & 4.5 & 3.8 & $* *$ \\
Professional journals & 5.7 & 6.0 & $\mathrm{~ns}$ \\
\hline${ }^{a}$ A higher score indicates more media coverage. & \\
${ }^{*} p<.05$. & & \\
${ }^{* *} p<.01$. & & \\
${ }^{* * *} p<.001$. &
\end{tabular}

are more negative about the benefits of science and technology than the Dutch; they assess the contribution to well being of society to be lower $(F(1,174)=10.26$, $p$ $<.001)$ as well as the contribution to economic development $(F(1,174)=6.83, p<.01)$ and the present level of prosperity $(\mathrm{F}(1,174)=9.60, \mathrm{p}<.001)$.

In Table $\mathrm{V}$, media coverage of information about energy sources in general is depicted. Significant differences were found between the countries. Inspecting the data, we see that the newspaper coverage is assessed significantly higher in the Netherlands $(F(1,171)=9.37$, $p<.01)$ and this is also the case for the radio $(F(1,171)$ $=5.17, \mathrm{p}<.05)$, but not for television $(\mathrm{F}(1,171)=$ $0.62, \mathrm{~ns})$. With regard to media exposure which is not depicted in Table IV, significant differences between the countries exist. The Dutch state that they are more exposed to information in the newspapers about the application of nuclear power $(\mathrm{F}(1,176)=14.57, \mathrm{p}<.001)$ 
and about the application of coal $(F(1,176)=20.29, p$ $<.001$ ).

\section{DISCUSSION}

One of the most remarkable results was that the French subjects had a higher risk perception and a more negative attitude toward nuclear power, which is clearly contrary to the observation of Weinberg. ${ }^{(8)}$ However, as we have noted before, due to our sampling method our subjects are not representative for the general populations of France or the Netherlands, so our data do not imply that the general French population has a more negative attitude toward nuclear energy than the Dutch. On the other hand, our data are in line with the results found in the empirical studies of Karpowicz-Lazreg and Mullet $^{(10)}$ and Bastide et al., ${ }^{(9)}$ which also contradict Weinberg's assumptions. The French subjects also assess the benefits of the use of nuclear power to be higher than the Dutch. It seems that this last result is not in agreement with their negative attitude. However, Midden $^{(4)}$ concluded that the public is primarily concerned with safety and benefits are always considered to be less important. Slovic ${ }^{(5)}$ also found that perceived dread was the most important factor. Our data indicate a high significant correlation $(.58)$ between attitude and risks and the relation with benefits was very low (.17). So the attitude toward nuclear power is mainly based on perceived risks and the advantages play a minor role in the eyes of the public. It is not surprising that the French more than the Dutch emphasize the importance of benefits of nuclear power, because their country is more dependent on this source of energy and on the short term will not be able to switch over to alternative sources. For coal, the Dutch show a more negative attitude and a higher risk perception and they tend to assess the benefits to be higher. This last result agrees with what we stated before; the Dutch are more dependent on coal.

How can the differences in attitude and risk perception between the two countries be explained? The density of the energy plants-France has a higher density of nuclear power plants as in the Netherlands is the case for coal fired plants-could be an explaining factor. We expected that the higher the density, the more people benefit directly or indirectly from nuclear power. Consequently their risk perception will be lower and their attitude less negative. Our results are quite contrary to this, because in France risk perception for nuclear power was higher than in the Netherlands and at the same time for coal the Dutch who have more coal fired plants, scored higher. But we also established that, compared to coal, in both countries risk perception for nuclear power was highest which in general does not fit with the density hypothesis; because of the higher density of coal fired plants in Holland risk perception should be lower in that country. So, to our opinion the differences in risk perception between France and the Netherlands can not be explained by the density hypothesis.

A second assumption is that differences in mass media exposure might explain this result. In previous work $^{(19)}$ we established that in mass media reports potential harms are often mentioned but seldom information about benefits. So, mass media have a preoccupation with bad news. On the basis of social learning theory it can be assumed that this negative bias in media reporting about technological hazards will bias the reactions of receivers who are frequently exposed to it. As we established, however, in France the coverage of information about energy sources in general seems to be lower and the French maintain that they are less exposed to information about nuclear power in the newspapers. So, for nuclear power mass media effects do not seem to be responsible for the differences between the countries. For coal, however, media effects may not be excluded, because in the Netherlands the coverage of information about energy sources is higher and, moreover, newspaper exposure to information about the application of coal is also higher. Due to this result may be that some years ago the Dutch government decided to switch over from natural gas to coal. This policy met a lot of criticism in the press and the public, and in the period before our study was performed news coverage about this issue was quite high. So, in the Netherlands mass media effects might explain the negative attitude and risk perception toward coal.

A third assumption is that the governmental policy is responsible for the differences between countries. French respondents assess their government to take a more favourable position toward nuclear power, and moreover, wants to regulate nuclear enterprise more than the Dutch. They also maintain that their country has a leading position in this area. However, they do have a more negative attitude and risk perception and intend more than the Dutch to protest against the application of nuclear power. At the same time they feel less capable to perform this protesting behaviour. It seems that the power of the repressive bureaucratic central government in France is responsible for the negative powerless reactions of the people. It is striking that the French subjects also indicate that they feel less capable to mitigate the risks of the large scale application of coal, which gives an indication of the strong repressive power of the central government in France. Bastide et al. ${ }^{(9)}$ also stress 
this political factor when they conclude that French environmentalist groups have been able to organize important anti nuclear demonstrations in the 70 's, but failed to represent a significant electoral force. By non participation of the man on the street the bureaucratic government seems to mobilize aversion and social dissent against nuclear power. This conclusion is quite opposite to Weinberg's assumption that in France nuclear power enjoys an atmosphere of acceptance. Toward coal the situation is reversed, here the French indicate that their government takes a less favourable position than in the Netherlands and that might be the reason why it is more accepted by the public in France.

Finally, an explanation might be that technology is higher developed in France which could be a source of concern. Slovic ${ }^{(5)}$ states that Americans face more risks today than in the past and future risks will even be greater, like in other highly industrialised nations. He is surprised that the richest, longest lived, best protected and more resourceful civilization is on its way to become the most frightened. We did establish that the French assess their own country to have a leading position with respect to nuclear power and had a higher risk perception and a more negative attitude toward nuclear power. The French are also more negative about the benefits of technology than the Dutch; they rate the contribution to well being of society to be lower as well as the contribution to economic development and prosperity. It seems that the perceived high level of technological development coincides with a more sceptical point of view.

\section{ACKNOWLEDGMENTS}

The authors would like to thank Ir. J. J. M. Snepvangers and the Stichting Energie Informatie for their assistance with this study.

\section{REFERENCES}

1. H. J. Otway, and M. Fishbein, Public Attitudes and Decision Making (IIASA, Laxenburg, 1977).

2. K. Thomas, D. Maurer, M. Fishbein, H. J. Otway, R. Hinkle, and D. Simpson, A Comparative Study of Public Beliefs About Five Energy Systems (IIASA, Laxenburg, 1979).

3. R. W. Meertens, and P. J. M. Stallen, "Beoordeling van Kernenergie: Evaluaties, Beliefs en Attitudes" (Assessment of Nuclear Energy: Evaluations, Beliefs and Attitudes). Nederlands Tijdschrift voor de Psychologie, 36, 45-55 (1981).

4. C. J. H. Midden, "Individu en Grootschalige Technologie: Een Vergelijkende Studie naar de Electriciteitsproductic met Kolen en Uraan" (Individual and Large Scale Technology: A Comparative
Study to the Production of Electricity with Coal and Uranium). Dissertation, Leiden, the Netherlands (1986).

5. P. Slovic, "Perception of Risk," Science, 236, 280-285 (1987).

6. D. D. L. Daamen, and J. Kips, De Energiemonitor: Trends in Publieksoordelen Over de Toepassing van Kernenergie, Kolen en Andere Energiebronnen ten Behoeve van de Electriciteitsproduktie (The Energy Monitor: Trends in Public Perception of the Application of Nuclaer Energy, Coal and Other Energy Sources for the Production of Electricity) (Ministry of Environmental Affairs, The Hague, 1993).

7. B. Verplanken, "Beliefs, Attitudes and Intentions Toward Nuclear Energy Before and After Chernobyl in a Longitudinal WithinSubjects Design," Environ. Behav., 21, 371-392 (1989).

8. A. M. Weinberg, "Nuclear Power and Public Perception," in M. Shubik (ed.), Risk, Organizations, and Society (Kluwer Academic Publishers, Dordrecht, the Netherlands, 1991).

9. S. Bastide, J. P. Moatti, J. P. Pages, and F. Fagnani, "Risk Perception and Social Acceptability of Technologies: The French Case," Risk Anal., 9, 215-224 (1989).

10. C. Karpowicz-Lazreg and E. Mullet, Societal Risk as Seen by the French Public, Risk Anal., 13, 253-258 (1993).

11. R. Maderthaner, G. Guttman, E. Swaton, and H. J. Otway, "Effect of Distance upon Risk Perception," J. Appl. Psychol., 63, 380382 (1978).

12. L. Harris, in B. D. Melber, S. M. Nealey, J. Hammersla, and W. L. Rankin (eds.), Nuclear Power and the Public: Analysis of Collected Survey Research (Battelle, Seattle, Washington, 1975).

13. J. Chiva, "Perception du Risque Autour de Quelques Centrale Nucléaire (Paper presented at Colloquium on the Risks of Different Energy Sources, Paris, 1980).

14. C. J. H. Midden, D. D. L. Daamen, and B. Verplanken, De Beleving van Energierisico's (The Perception of Energy Risks) (Ministery of Environmental Affairs, The Hague, 1983).

15. G. O. Rogers, "Residential Proximity, Perceived and Acceptable Risk," in R. A. Waller and V. T. Covello (eds.), Low Probability, High Consequence Risk Analysis (Plenum Press, New York, 1984), pp. 507-520.

16. L. Festinger, $A$ Theory of Cognitive Dissonance (Stanford University Press, Stanford, 1957).

17. A. Bandura, Social Foundations of Thought and Action (Prentice Hall, Englewood Cliffs, NJ, 1986).

18. E. Singer and P. Endreny, "Reporting Hazards: Their Benefits and Costs," J. Commun., Summer, 10-27 (1987).

19. O. Wiegman, J. M. Gutteling, H. Boer, and R. J. Houwen, "'Newspaper Coverage of the Technological and Environmental Hazards and the Reactions of Readers," Journ. Quart., 66 (winter), 844 852,863 (1989).

20. R. E. Kasperson, O. Renn, P. Slovic, H. S. Brown, J. Emel, R. Goble, J. X. Kasperson, and S. Ratick, "The Social Amplification of Risk: A Conceptual Framework," Risk Anal., 8, 177-187 (1988).

21. O. Renn, W. J. Burns, J. X. Kasperson, R. E. Kasperson, and P. Slovic, "The Social Amplification of Risk: Theoretical Foundations and Empirical Applications," J. Soc. Issues, 48, 137-160 (1988).

22. CBS (Dutch Census Bureau), "Statistisch Zakboekje 1993" (Statistical Pocketbook 1993) (The Hague, 1993).

23. J. M. Gutteling, "A Field Experiment in Communicating a New Risk: Effects of the Source and a Message Containing Explicit Conclusions," Basic Appl. Soc. Psychol., 14, 295-316 (1993).

24. O. Wiegman, J. M. Gutteling, and H. Boer, "Verification of Information Through Direct Experiences with an Industrial Hazard," Basic Appl. Soc. Psychol., 12, 325-339 (1991).

25. O. Wiegman and J. M. Gutteling, "Risk Appraisal and Risk Communication: Some Empirical Data from the Netherlands Reviewed," Basic Appl. Soc. Psychol., 16, 227-249 (1995). 